\title{
O poema no livro didático: abordagens e formação de leitores
}

\author{
Margarete Petri da Rosa ${ }^{1}$ \\ Maria Iolanda Monteiro²
}

\begin{abstract}
Resumo
Este trabalho é resultado de uma análise sobre o tratamento conferido ao poema nos livros didáticos de Língua Portuguesa, tendo em vista a formação de leitores literários. Para isso, foram selecionados quatro manuais didáticos utilizados por escolas públicas no interior do estado de São Paulo. Tal investigação, pautada na metodologia qualitativa, aborda a trajetória da poesia infantil no Brasil, a presença dos poetas na produção literária e a abordagem do poema nos livros e, por fim, as contribuições do livro na formação leitora. Os objetivos propostos partem do pressuposto de que a poesia está presente na história social dos seres humanos, portanto, faz-se necessário que as crianças tenham contato com esse gênero já nos anos iniciais da educação básica.

Palavras-chave: Poemas Infantis; Livros Didáticos; Análise de Conteúdo; Tratamento Poético; Formação Leitora.
\end{abstract}

The poem in the textbook: approaches and reader formation

\section{Abstract}

This paper results from an analysis on the handling of the poem in Portuguese Language textbooks regarding foremost the formation of literary readers. For this purpose, four instructional handbooks used in public schools from São Paulo state in 2015 were chosen. Such research, based on a qualitative methodology deals with the trajectory of children's poetry in Brazil, the presence of poets in literary production and the poetic approach within the analyzed books and, finally, the contributions of the book in shaping young readers. The suggested objectives sprout from the assumption that poetry is present in social history of humankind, therefore it is necessary that children have contact with this genre beginning on the initial years of basic education.

Keywords: Children's Poems; Textbooks; Content Analysis; Poetic Treatment; Formation of Readers.

\section{Considerações iniciais}

Este artigo apresenta resultados de uma análise de livros didáticos de Língua Portuguesa do 50 ano do Ensino Fundamental, cujo objetivo central era investigar e discutir a abordagem do gênero poema. Em outras palavras, procurou-se, por meio de uma amostragem, analisar como tais manuais organizam e apresentam os poemas às crianças, tendo em vista, sobretudo, a formação de leitores de textos poéticos. Para isso, foram selecionados quatro livros didáticos

\footnotetext{
1 Pedagoga formada pela Universidade Federal de São Carlos (UFSCar). Ouro Branco - MG. E-mail: margaretpetry@gmail.com.

2 Professora Associada I do Departamento de Teorias e Práticas Pedagógicas e do Programa de Pós-Graduação da Universidade Federal de São Carlos (UFSCar). São Carlos - SP. E-mail: mimonteiro@ufscar.br.
} 
utilizados por escolas públicas estaduais do interior de São Paulo, em 2015. Estabeleceram-se também dois eixos de análise: sendo que o primeiro contém uma análise e discussão sobre o tratamento dado ao poema e, no segundo, optou-se por compreender que tipo de leitor poético o livro pretende formar por meio dos poemas selecionados.

Esta investigação se justifica à medida que contribui para preencher as ausências em relação ao estudo da poesia nas escolas de anos iniciais, bem como contribuir para reflexões acerca da vivência poética na escola, entendendo que a poesia está presente na própria história individual e social dos seres humanos, por meio das cirandas, parlendas, canções de ninar que marcam a infância, algumas festas religiosas ou festivas, assim como mostram Aguiar e Ceccantini (2012). Neste sentido, foi necessário, de início, situar e compreender historicamente o trajeto da poesia infantil em nosso país, pois foi a partir do século XX que ela começou a ganhar maior visibilidade, o que não quer dizer que anteriormente não tenha havido registros de poesia, contudo, havia pouco espaço no mercado editorial, conforme destaca Abramovich (1999).

Diante disso, este artigo se estrutura em função da análise de alguns poemas presentes nos livros didáticos, assim como das proposições de atividades. Vale ressaltar que este trabalho parte da concepção de poema como um gênero textual estruturado em versos, com ritmo e que pode conter rima ou não. Neste sentido, buscou-se verificar se as atividades propostas não se resumiam apenas em pretexto para ensinar conteúdos gramaticais. Além disso, teve como objetivo analisar se os textos poéticos apresentavam uma linguagem rica em relação à materialidade poética, como figuras de linguagem, recursos semânticos e expressivos, jogos visuais e sonoros, dentre outros.

Importante destacar que tais objetivos foram propostos tendo em vista que a poesia compõe a história social dos seres humanos, sendo assim, assume um papel muito importante na construção da tradição literária, daí a importância de que os alunos e alunas tenham contato com essa forma de linguagem já nos anos iniciais da educação básica. Além disso, o poema pode se constituir em um mecanismo de ensino e aprendizagem produtivo, sobretudo nos anos iniciais, pois propicia o contato com os recursos semânticos e expressivos, bem como o desenvolvimento da apreciação estética.

Para a construção deste trabalho, utilizaram-se autores diversos que tratam da poesia 
infantil no Brasil, os quais serviram de apoio para a fundamentação teórica. Além disso, foi solicitado a quatro escolas distintas um exemplar de um livro didático de Língua Portuguesa do 50 ano, a fim de realizar a análise. Os procedimentos metodológicos seguiram as orientações da pesquisa qualitativa para a coleta e análise dos dados, conforme os subsídios teóricos de Lüdke e André (1986). As análises sobre o tratamento que os livros didáticos conferem ao poema se fundamentam na metodologia de revisão bibliográfica e análise de conteúdo, visto que busca identificar, descrever e estabelecer interpretações e implicações possíveis acerca das possibilidades poéticas que esses manuais apresentam às crianças.

Ao longo das análises, os livros foram nomeados pelas seguintes letras: A, B, C e D, com o intuito de facilitar as recorrentes referências ao longo deste texto. Optou-se por não explicitar quais escolas públicas cederam os materiais didáticos, tendo em vista que o objetivo não era o de conhecer suas concepções em relação ao ensino da língua. E, finalmente, os manuais didáticos analisados foram propostos pelos seguintes autores: Vasconcelos (2011), Cavéquia (2014), Prado e Hülle (2011) e Sanchez (2011).

\section{A poesia infantil no Brasil}

A infância, segundo Martha (2012), foi um elemento que colaborou com a recuperação de antigas canções folclóricas, as quais foram sendo resgatadas coletivamente e adaptadas à cultura do grupo, portanto, as crianças, ao fortalecerem a transmissão oral, acabaram por colocar "sua memória e seu poderoso instinto de imitação a serviço da preservação da poesia popular (...)" (p.45). Percebe-se, então, o quão importante foi o papel da infância para a afirmação do poema, pois a produção popular acabou por gerar uma tradição de composições inerentes ao universo infantil, visto que eram as crianças as destinatárias das cantigas de ninar, parlendas, trava-línguas, cantigas de roda, quadrinhas folclóricas e folguedos.

Diante dessas considerações, faz-se necessário compreender um pouco da trajetória da poesia infantil no contexto brasileiro. Sobre isso, Aguiar e Ceccantini (2012) apontam que ela se constituiu no Brasil como um gênero tardio, assim como as outras manifestações literárias, datado nas últimas décadas do século XIX. Anteriormente, a poesia costumava aparecer em versos afetivos, escritos, muitas vezes, em datas natalícias pelos familiares da criança. Alguns 
desses versos chegaram a ser transcritos nas obras de seus autores, no entanto, não eram voltados, propriamente, à infância.

Em 1882 tem-se o registro do livro: Poesias infantis, de José Fialho Dutra, todavia, o autor apresenta uma concepção adulta, "desenvolvendo temas cívicos, escolares, religiosos e sentimentais, em tom exemplar e normativo" (AGUIAR; CECCANTINI, 2012, p.12). Em 1904, Olavo Bilac escreve o livro Poesias Infantis, propagando a ideia de se educar via poesia, contudo, já se percebe uma tentativa de adequar os textos ao seu destinatário específico, pois o poeta se propôs a criar poemas que não fossem difíceis ao entendimento das crianças.

Aguiar e Ceccantini (2012) afirmam que tal postura merece elogios, pois a crítica contemporânea desconsidera essa preocupação de Bilac quando enfatiza apenas o caráter educativo de sua produção. A intenção pedagógica aliada à adequação estética ao público infantil fez com que a obra fosse muito lida e muito indicada pelos professores. Segundo os autores, Bilac foi responsável por inaugurar, na tradição poética brasileira, a concepção de uma poesia voltada ao ensino, utilizando os versos como uma forma de transmitir conteúdos morais e disciplinadores.

Sorrenti (2009) também discute a questão da doutrinação via poesia, pois, de um lado, quem escreve para a criança é um adulto, sendo assim, "a visão do mundo que se imagina ser a da criança, ou quem sabe, a visão que o adulto quer que ela possua" (p.15), por vezes, acaba prevalecendo. Por outro lado, a autora afirma que a criança distingue bem a poesia com esse caráter. Além disso, há poesia considerando a infância e oferecendo possibilidades de combinação entre sons e imagens de forma a satisfazer o gosto pela criatividade e experimentação linguística.

Para Aguiar e Ceccantini (2012), Henriqueta Lisboa, em 1943, por meio da publicação do livro $O$ menino poeta, é quem promove uma ruptura com a estrutura pedagogizante, predominante até então na literatura infantil, "privilegiando o lirismo, utilizando largamente a metáfora e o ritmo breve, investindo nas brincadeiras onomatopaicas" (p.13). Essa poeta soube, de acordo com os autores, realizar um aproveitamento de elementos folclóricos de maneira bastante criativa, e isso se tornou uma tendência marcante na produção literária voltada às crianças.

Apesar de Aguiar e Ceccantini (2012) inserirem Henriqueta Lisboa em um momento de 
ruptura com o caráter pedagógico, Mello (1995), ao discutir a questão da poesia infantil no Brasil, é convicta ao afirmar que, anterior à publicação de Ou isto ou aquilo (MEIRELES, 1964), não havia uma poética que se destinasse ao público infantil, já que as publicações refletiam apenas a lógica do mundo adulto, isto é, "(...) o sujeito da enunciação - eu-lírico - assinala claramente a sua consolidada cosmovisão, posicionando-se em situação de superioridade (...)" (MELLO, 1995, p.150).

Turchi (1995) destaca ainda que "quando se tratava de poetizar para crianças, o cunho pedagógico-moralizante acabava por prevalecer" (p.156). Sob essa tradição já foi destacado Bilac, mas a autora assinala que embora em $O$ menino poeta (Henriqueta Lisboa) já se perceba uma ação voltada mais para o caráter lúdico da criação poética, avançando para a experimentação, há ainda uma espécie de manutenção de valores convencionais e apenas um aceno para um possível rompimento com a tradição poética destinada à infância.

Acerca dessa questão, Turchi (1995) aponta que, nesse período inicial de produção de poemas, incluem-se aqueles que se tornaram escritores ao elaborarem textos literários para os livros didáticos, propagando uma visão adulta e uma linguagem com formas desgastadas, versos com rimas mal construídas e assuntos piegas. Neste sentido, aponta que a obra Ou isto ou aquilo funciona como um divisor de águas e instaura a poesia infantil, trazendo a ideia de uma poética que "agora consagra uma produção que privilegia a visão da criança na contemplação de mundo, bem como suas necessidades e seus sonhos" (p.151).

Segundo Turchi (1995), os poemas de Cecília Meireles começam, no plano temático e expressivo, a refletir as fórmulas presentes na tradição folclórica e a retratar temas inerentes ao cotidiano infantil, bem como suas relações com o mundo. Os temas, antes intocáveis e considerados inadequados, como a brevidade e finitude da vida, começam a aparecer. Diante disso, a autora mostra que, no tocante à linguagem, os poemas para a infância vão se utilizar do jogo de palavras, quebra de discursividade, retomada de elementos folclóricos e a exploração da sonoridade, assim como ocorre nas quadras, nos trava-línguas, nas adivinhas e nas parlendas.

No mesmo período de produção de Cecília Meireles, Sidônio Muralha e Vinicius de Moraes se constituem também em paradigmas por meio das seguintes obras: $A$ televisão da bicharada (1962) e A Arca de Noé (1974), respectivamente. Após a produção desses três poetas 
maiores e a instauração de novos rumos na poesia infantil brasileira, torna-se impossível, devido à variedade e originalidade poética, enquadrar a poesia em limites rígidos e pré-fixados.

Para Zilberman (2005), a poesia propriamente infantil surgiu apenas nos anos 1980. José Paulo Paes é, na perspectiva da autora, o poeta que "melhor esclarece o que significa escrever versos para as crianças" (p.129), pois consegue estabelecer conexão entre brincadeira e escrita, fazendo com que o pequeno leitor aprecie seus textos. Em Poemas para Brincar, o poeta destaca o aspecto lúdico, suas comparações se referem ao universo infantil, "pois são os pequenos que brincam com bola, papagaio ou pião, sugerindo que a diversão e o jogo se evidenciam melhor em textos orientados para eles" (ZILBERMAN, 2005, p.129).

De acordo com Zilberman (2005), foi somente a partir dessa década que começou a se valorizar o caráter lúdico da linguagem, expandindo assim a poesia infantil. Além disso, destaca que a partir das produções de Roseana Murray, Elias José, Sérgio Caparelli, Ferreira Gullar, Manoel de Barros, os versos começaram a ganhar outra expressão pautada na diversão, no jogo e na brincadeira, promovendo outras escritas e libertando os textos do moralismo, pedagogismo e civismo.

O estudo da trajetória da poesia infantil no Brasil mostra que, após 1980, os versos e estrofes começaram a colocar as crianças como protagonistas. Diante disso, Sorrenti (2009) aponta que, longe dos ideais moralizantes, didáticos e pedagógicos, a poesia contemporânea caminha no sentido de desfazer os clichês, as metáforas já consolidadas e propõe a restauração da palavra. Os propósitos pedagógicos cedem lugar ao pensamento poético esteticamente comprometido com a arte, portanto, isso precisa ser considerado pela escola no momento de abordar os poemas.

Apesar de haver alguns desacordos entre os pesquisadores ao situarem os poetas em seus momentos históricos, é interessante destacar o posicionamento de Coelho (2000) e Sorrenti (2009) em relação às diferenças básicas de propósitos entre a poesia tradicional e a contemporânea, dado que a primeira pretendia "levar a criança a aprender algo para ser imitado depois" (Sorrenti, 2009, p.23), ao passo que a contemporânea tem como intenção levá-las a descobrir e experimentar novas vivências que poderão ser incorporadas em seu desenvolvimento. 


\section{O poeta e a infância: o tratamento conferido ao poema nos livros didáticos}

Os livros analisados apresentam uma grande diversidade de gêneros textuais, demonstrando que há uma preocupação em atender as indicações dos Parâmetros Curriculares Nacionais de Língua Portuguesa (BRASIL, 1997), visto que tal documento define que o objetivo dessa área é expandir as possibilidades do uso da linguagem, sintetizadas em quatro habilidades linguísticas: falar, escutar, ler e escrever. O referido documento destaca ainda que os usos da linguagem são determinados historicamente, de acordo com as necessidades sociais do momento, daí a necessidade de se conhecer os mais diversos gêneros, inclusive o poema.

Tendo isso em vista, este eixo de análise tem como objetivo compreender os propósitos do livro ao apresentar os poemas e, em seguida, construir algumas concepções sobre que tipo de leitor pretende formar. De forma geral, constatou-se que os livros apresentam diversos poetas que se dedicaram a escrever para o público infantil, como José Paulo Paes, Sérgio Caparelli, Elias José e Ferreira Gullar, mas também apresentam autores que não escreveram especificamente para as crianças, como Manuel Bandeira e Mário Quintana.

Além dessa constatação, vale destacar que os livros A, B e D apresentam uma variedade de poemas com objetivos diversos, todavia, o livro $C$ não se detém nesse gênero com profundidade. Após essas considerações, convém agora adentrar no universo poético apresentado em cada livro, buscando analisar, sobretudo, a abordagem e o tratamento conferido a esse gênero, pois, conforme mostram as análises de manuais didáticos de Língua Portuguesa realizadas por Vieira (2015), embora os livros tragam textos interessantes, em geral, há o predomínio de atividades que visam à extração de informações em detrimento da função social do texto, desconsiderando, portanto, sua mensagem principal.

O livro A traz inicialmente os seguintes poemas: Lisboa: aventuras (José Paulo Paes), $A$ lua cheia (José Antonio Dávila) e Cachorros e gatos (Roseana Murray). O primeiro poema visa à discussão das variações geográficas da Língua Portuguesa. O segundo é utilizado para abordar a classe gramatical adjetivo e o terceiro foi empregado para tratar da classe gramatical substantivo, revelando que "o estudo do gênero poema possui diversificados tratamentos, às vezes ele é técnico, outras vezes já aparece mais preocupado com o conteúdo" (VIEIRA, 2015, p.78). Neste sentido, vale destacar que, conforme Vieira (2015), quando a abordagem poética é 
realizada apenas de maneira técnica, promove-se um apagamento do elemento estético do poema.

Observa-se que, de início, o livro A utiliza apenas os poemas como pretexto para abordar categorias gramaticais, sem se ater à estrutura do gênero, à análise do texto e à linguagem poética. Todavia, nas propostas seguintes, as atividades se tornam mais complexas e dialogam, inclusive, com outras linguagens, possibilitando a produção textual, ainda que não seja propriamente de poema. A partir dessas considerações, torna-se importante tratar dessas propostas de forma mais detalhada. Há, ainda, nas atividades a possibilidade de discutir com as crianças sobre a capacidade do poema de jogar com as palavras, estabelecendo, assim, outros sentidos para o texto, no entanto, há momentos em que se limita à categorização gramatical, ou seja, não colocam as crianças em situação mais ativa, pois cabe a elas apenas realizar inferências, localizar informações, lidar com conceitos e realizar categorizações gramaticais.

O livro traz uma atividade com o poema Os estatutos do homem, de Thiago de Mello, com a proposição de questões inferenciais para o levantamento de hipóteses a partir do título. Após a leitura, propõe-se estabelecer a relação do poema com as leis, já que é estruturado para dar ideia de que se lê uma lei/decreto, conforme se vê no excerto abaixo extraído do livro didático:

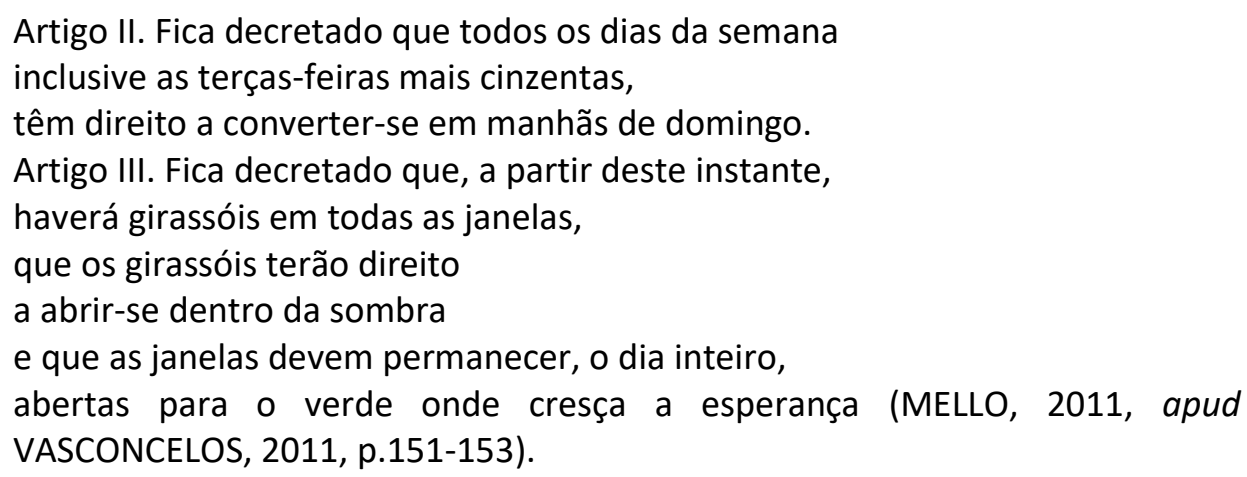

Esse poema, bem como as atividades propostas, possibilita à criança pensar sobre a linguagem conotativa e os símbolos gráficos presentes nos textos de lei. Além disso, traz à discussão uma questão de ordem moral e, para isso, utiliza-se dos seguintes versos do artigo $\mathrm{V}$ do poema Os estatutos do homem: "Fica decretado que os homens / estão livres do jugo da mentira" (VASCONCELOS, 2011, p.152). Com isso, propõe que se pense nas consequências da mentira. Percebe-se que essa atividade busca trazer as concepções das crianças sobre algumas 
situações e a pensar em qual decreto seria mais importante para suas vidas, levando-as a refletir, de forma mais ativa, sobre as questões apresentadas.

Algo interessante é que essa proposta reserva um momento para a produção de um cartaz com alguns artigos e com uma ilustração a ser apresentada ao fim da unidade. Ainda que não seja propriamente a escrita de um poema, a unidade propõe também que se crie um estatuto de proteção aos animais que, ao final, deverá compor um estatuto coletivo. Para isso, apresenta alguns direitos dos animais presentes na Declaração Universal dos Direitos dos Animais, criada pela UNESCO, em 1978.

Logo em seguida, o livro A traz o poema Meninos carvoeiros, de Manuel Bandeira, porém, traz antes um pequeno texto que trata do Estatuto da Criança e do Adolescente, de 1990, e sobre o trabalho infantil, destacando que o poema, escrito em 1921, já chamava a atenção para uma problemática social. Além disso, propõe algumas questões inferenciais sobre uma ilustração, promovendo, assim, um diálogo entre ambos. Após a leitura, a atividade propõe a intepretação de alguns versos, o efeito semântico de determinadas palavras, a cópia de informações, a compreensão da função de recursos textuais e das variações linguísticas presentes na oralidade e a reflexão sobre essa forma de exploração.

Em contraposição ao livro A, o livro B dedica uma unidade somente para abordagem do poema. Para isso, inicia com Convite, de José Paulo Paes. Em seguida, apresenta um texto informativo e o poema As algas, de Elias José, para que as crianças identifiquem a diferença de estrutura entre os dois gêneros. As propostas de atividades nessa unidade são interessantes, pois abordam as duas modalidades de interpretação: oral e escrita. Além disso, ao estabelecer a comparação entre os dois tipos de texto (informativo e o poema) chama a atenção para a construção das rimas e a forma sensível e incomum que a linguagem pode assumir nos poemas, em contraste à linguagem presente no texto informativo.

Posterior a essa distinção entre os textos, o livro traz o poema visual Canção para ninar gato com insônia, de Sérgio Caparelli, e propõe a comparação com a estrutura do poema apresentado anteriormente. Importante destacar que esse poema é construído apenas com onomatopeias, sendo assim, o autor do livro apresenta o conceito e exemplifica. Logo em seguida, apresenta mais dois exemplos: $A$ árvore (Ricardo da Cunha Lima) e A lesma (Leo Cunha), e solicita às crianças que produzam poemas visuais. 
Após esse momento de produção escrita, o livro traz um poema narrativo de cordel denominado No reino dos insetos (o casamento), de Ado Benatti. Esse cordel é todo rimado, conferindo, assim, ritmo à leitura. As questões propostas são diversas e vão desde a interpretação, compreensão de metáforas, localização de rimas, estrofes e versos até a explicitação de categorias gramaticais de vocábulos e a significação das palavras, além da proposição de que se transforme o poema em uma prosa.

A leitura de cordéis em sala de aula, de acordo com Marinho e Pinheiro (2012), contribui para a ampliação do "repertório infantil da convivência das crianças com os bichos e, sobretudo, sua capacidade de brincar com os ritmos da língua e os voos da fantasia" (p.61), pois, nos espaços em que há pouco contato com a literatura oral mediada pelos adultos, torna-se necessário criar contextos que possibilitem apresentar o cordel às crianças, visto que esse gênero apresenta traços de fantasia, inventividade frente a situações inusitadas e riqueza sonora devido à musicalidade.

A unidade 8 , do livro $B$, traz à discussão a temática do trabalho infantil e apresenta uma série de textos para discutir essa questão, por exemplo, o poema 1 é 5, 3 é 10!, de Santuza Abras, em que o eu poético retrata a condição de um menino que desce o morro para trabalhar. As questões propostas visam à interpretação, localização de características que comprovam se tratar de um poema. Posteriormente, a autora do livro aponta que poemas não tratam apenas de assuntos ou temas leves, mas podem também abordar questões sociais e temas tristes, como fome, miséria, trabalho infantil, dentre outros. Para isso, apresenta outros poemas, conforme se vê abaixo:

\author{
Greve \\ As panelas das favelas \\ fazem greve de fome. \\ Faz mil e tantos anos \\ que não cozinham sonhos \\ pros meninos sem nome. (DINORAH, 1986, apud CAVÉQUIA, 2011, p.165). \\ Menor abandonado \\ São tantos os menores \\ abandonados pelas calçadas \\ que um dia os maiores \\ acabam tropeçando neles \\ e param de fingir \\ que ainda não notaram (TAVARES, 1997, apud CAVÉQUIA, 2011, p.165).
}

Periódico Horizontes - USF - Itatiba, SP - Brasil - e021025 
Os dois textos servem para a proposição de escrita de poemas que tratem problemas sociais. Para isso, a autora oferece algumas dicas, por exemplo, a utilização ou não de rimas, liberdade na quantidade de versos e estrofes e propõe a criação de um livro. Por fim, na última unidade, o livro B traz diversos textos cômicos, como os poemas O que me faz rir (Gianni Rodari), Se você for inventor invente (José Paulo Paes), Limerique (Edward Lear) e uma quadrinha popular, evidenciando que o poema pode ser um momento de jogo e de diversão.

A partir da leitura dos poemas com humor, propõe atividades de interpretação oral e escrita e a localização das rimas, apresentando também a possibilidade de as crianças produzirem seus próprios poemas com o objetivo de divertir o leitor. Para isso, sugere três assuntos, quais sejam: um sapo que tem chulé, uma formiga apaixonada por um tamanduá, uma briga entre o sol e a lua, no entanto, deixa claro que é possível criar outros temas. O livro traz algumas dicas sobre a estrutura do poema e sugere a confecção de um mural para que mais pessoas possam se divertir com a leitura.

O livro $\mathrm{C}$, apesar de trazer diversos gêneros textuais, apresenta apenas o texto: $O$ menino que ganhou um rio, de Manoel de Barros, propondo questões que exigem a interpretação pessoal, a transcrição de versos do poema e a compreensão do efeito de sentido de algumas palavras. O poema está inserido em uma unidade que trata do gênero relato pessoal, sendo assim, é apresentado com a finalidade consolidar as características desse gênero, já que as crianças são solicitadas a produzi-lo. É possível afirmar que a apresentação do poema, atrelado ao gênero relato pessoal, assenta-se em uma característica peculiar da obra desse poeta que, muitas vezes, assume um discurso memorialista, com marcas autobiográficas, conforme mostra Silva (2012).

Por fim, o livro D traz uma diversidade maior, mas se concentra apenas em aspectos gramaticais da língua. No entanto, há uma proposta de atividade com o poema Amor, de Lalau e Laurabeatriz, que busca abordar, de forma mais complexa, a estrutura do gênero. Para isso, a autora apresenta o conceito de imagem poética, conforme se vê no excerto explicativo retirado do livro:

Na criação poética, são feitas associações de ideias para produzir emoção. 0 significado de algumas palavras se une ao de outras para produzir imagens poéticas. Uma dessas imagens recebe o nome de comparação. 
A comparação relaciona seres e ideias, pessoas e coisas, destacando suas características semelhantes ou traços comuns (SANCHEZ, 2011, p.73).

A breve explicitação do conceito foi apresentada com o objetivo de levar as crianças a compreenderem e a localizarem as imagens poéticas presentes no poema Amor, visto que solicita que criem a partir desse recurso, afirmando que "atribuir às palavras significados diferentes dos que são normalmente encontrados no dicionário é um recurso da linguagem poética" (SANCHEZ, 2011, p.74). Ainda sobre isso, a autora traz um excerto da história de Fernão Capelo Gaivota, de Richard Bach, para mostrar que essas imagens podem aparecer também em outros textos, visto que "a linguagem poética não aparece apenas em poemas. Textos em prosa também podem empregá-la. É o que se chama de prosa poética" (SANCHEZ, 2011, p.74). O livro apresenta também um poema de Adriana Falcão que exemplifica a utilização da linguagem conotativa:

\section{Tristeza}

é uma mão gigante que aperta o seu coração

Alegria

é um bloco de carnaval que não liga se não é fevereiro (FALCÃO, 2001, apud SANCHEZ, 2011, p.75).

Por meio dessas duas imagens poéticas, a proposição é que as crianças pensem em definições não dicionarizadas para os sentimentos de alegria e tristeza e compare-as com os significados presentes no dicionário. Por fim, solicita que expliquem o sentimento de amizade a partir da linguagem poética. Esse é o único momento em que o livro possibilita que as crianças sejam criadoras de poemas. Embora não estimule a criação de outros textos poéticos, já se observa uma possibilidade de a criança produzir seus próprios textos, considerando a potencialidade da palavra poética.

As análises iniciais revelam que cada livro didático aborda o poema de forma diferente, mas convergem em alguns pontos. $\mathrm{O}$ livro $\mathrm{A}$, apesar de trazer alguns poemas lúdicos, concentrase apenas em interpretação e utiliza como pretexto para ensinar categorias gramaticais ou introduzir outros gêneros textuais. Além disso, não aborda a questão da oralidade, desconsiderando que isso possibilita a compreensão dos jogos sonoros, rimas e aliterações. 
O livro $\mathrm{B}$, sendo o único que dedica uma unidade específica para tratar dos poemas, em diversos momentos aborda as possibilidades de leitura e escrita e propõe questões de interpretação oral. Embora em algumas propostas utilize o poema para introduzir categorias gramaticais, não se atém apenas a isso. Além disso, aborda também o poema de cordel, gênero literário que não aparece nos demais livros analisados.

O livro $\mathrm{C}$, embora apresente um poema interessante do ponto de vista da materialidade poética, não trabalha a produção escrita, limita-se apenas às questões de interpretação e de elementos caracterizadores desse gênero. Por fim, o livro D utiliza o poema, na maioria das vezes, para introduzir categorias gramaticais. Em apenas um momento propõe a escrita, colocando, assim, a criança na condição de escritora de poemas, entretanto, não aborda isso com profundidade.

A partir das análises, pode-se apontar que, em certos livros didáticos de Língua Portuguesa, a escolha de poemas está ligada "aos núcleos temáticos estudados, à exploração puramente da gramática, da interpretação de texto e algumas sugestões de criação" (VIEIRA, 2015, p.79). Além disso, conforme destaca Vieira (2015), a referência aos aspectos estéticos é feita mais como uma forma de curiosidade, e o poema, se comparado aos outros gêneros de texto, aparece em quantidade menor nos manuais didáticos.

Diante dessas considerações e dos poetas apresentados nos livros didáticos analisados, torna-se se importante compreender também quem foram os poetas/poetisas que escreveram para a infância, entendendo que as crianças gostam de experienciar as diversas manifestações poéticas, as semelhanças e os contrastes sonoros, como no caso dos trocadilhos, aliterações, onomatopeias, assonâncias, rimas e ritmos, pois, segundo Coelho (2000), o jogo de palavras pode funcionar como um fator de atração que provoca emoções, sensações e impressões em um movimento de interação lúdica.

Ao analisar a cronologia das produções dos poetas modernos, Zilberman (2005) sistematiza algumas informações importantes que auxiliam na compreensão do período e características principais de alguns poetas relevantes para a literatura infantil brasileira. Sendo assim, aponta que Mario Quintana pertence à Geração de 30, ao passo que José Paulo Paes, Ferreira Gullar e Manoel de Barros inserem-se no período da poesia concretista. Além disso, destaca que, enquanto alguns poetas escreveram apenas um ou dois livros de poesia infantil, 
outros se especializaram em produzir exclusivamente para esse público, como Sérgio Caparelli, Roseana Murray e Elias José.

Zilberman (2005) afirma que, depois de 1980, descobriu-se a poesia para crianças, não que antes não houvesse poemas para elas, no entanto, "a valorização do lúdico da linguagem propiciou a expansão da poesia endereçada à infância (...)" (p.129), incorporando, nos versos e nas estrofes, a diversão, o jogo e a brincadeira. Dessa forma, os poemas foram perdendo as características experimentadas na primeira metade do século $X X$, pois o "elenco de autores diversificou-se, e várias possibilidades expressivas apareceram (...)” (p.130).

Ainda sobre a questão da ampliação da escrita de livros de poemas para crianças, Lajolo e Zilberman (1999) apontam que essa produção não se solidificou apenas em termos quantitativos, mas também em diversidade e qualidade, deixando de lado os traços didáticos e pedagógicos. Destacam ainda que, na contemporaneidade, o poeta e a criança se encontram por meio da tematização do cotidiano infantil, "ou pela adoção, por parte do autor, de um ponto de vista que compartilha com seus pequenos leitores a anticonvencionalidade, quer da linguagem, quer do recorte de realidade (...)" (p.148).

Essa característica da anticonvencionalidade aparece nos poemas Se você for inventor invente (José Paulo Paes), Limerique (Edward Lear) no livro B e no poema O menino que ganhou um rio (Manoel de Barros) no livro C. Todavia, Lajolo e Zilberman (1999) explicitam que o fato de alguns poetas buscarem inspiração no cotidiano, ou assumirem o olhar infantil, não impede que a poesia moderna trate de temáticas sérias, conforme se vê nos poemas Greve (Maria Dinorah) e Menor abandonado (Ulisses Tavares), presentes no livro B, e Meninos Carvoeiros, no livro A.

Outro aspecto que Lajolo e Zilberman (1999) mostram é que alguns poemas inovadores podem fazer uso apenas de onomatopeias, recuperando, por exemplo, as vozes/sons dos animais de forma lúdica, como ocorre no poema visual Canção para ninar gato com insônia (Sérgio Caparelli) presente no livro B. Ainda sobre as formas lúdicas, Turchi (1995) destaca que Caparelli brinca com as construções verbais e instaura a comicidade nas situações ilógicas, assim como faz José Paulo Paes, reaproveitando a tradição fundamentada na oralidade, com a substituição do eu lírico adulto pela voz, de forma a transparecer a perspectiva de meninos e meninas, revelando seus anseios e descobertas. 


\section{O livro didático e a formação de leitores/escritores de poemas}

Para compor este eixo foram selecionados quatro poemas com o objetivo de compreender que tipo de leitor poético tais livros pretendem formar. Do livro A foi extraído o poema Meninos Carvoeiros, do livro B optou-se por selecionar Se você for inventor invente. No caso do livro C não foi necessário realizar uma seleção, pois há apenas um: O menino que ganhou um rio. Por fim, no livro $D_{\text {, }}$ selecionou-se o poema Amor. Vale destacar que este recorte possibilita uma análise parcial sobre as potencialidades do livro ao fornecer textos poéticos para as crianças. Posto isso, segue abaixo o poema: Meninos Carvoeiros (Manuel Bandeira), cuja proposição é diferente dos demais, visto que apresenta um tema mais sério, possibilitando a discussão de um problema social:

Passam a caminho da cidade.

- Eh, carvoero!

E vão tocando os animais com um relho enorme.

Os burros são magrinhos e velhos.

Cada um leva seis sacos de carvão de lenha.

A aniagem é toda remendada.

Os carvões caem.

(Pela boca da noite vem uma velhinha que os recolhe, dobrando-se com um gemido.)

- Eh, carvoero!

Só mesmo estas crianças raquíticas

Vão bem com estes burrinhos descadeirados.

A madrugada ingênua parece feita para eles

Pequenina, ingênua miséria!

Adoráveis carvoeirinhos que trabalhais como se brincásseis!

-Eh, carvoero!

Quando voltam, vêm mordendo num pão encarvoado,

Encarapitados nas alimárias,

Apostando corrida,

Dançando, bamboleando nas cangalhas como espantalhos desamparados (BANDEIRA, 1993 apud VASCONCELOS, 2011, p.166-167).

Ao tratar a questão do trabalho infantil, o poema substitui a ideia de humor pela reflexão, e a ludicidade confere lugar à seriedade. Diversas imagens são construídas pelo eu poético para 
intensificar a ideia de uma infância explorada, dada a ausência de condições materiais de existência dos meninos carvoeiros. Tais imagens aparecem nos versos em que a aparência física dos meninos é comparada com a dos burrinhos: "Só mesmo estas crianças raquíticas/ Vão bem com estes burrinhos descadeirados". Além desses, o último verso mostra, de certa forma, um apagamento desses meninos: "Dançando, bamboleando nas cangalhas como espantalhos desamparados" (BANDEIRA, 1993 apud VASCONCELOS, 2011, p.166-167).

Apesar de Bandeira não ter escrito especificamente para a infância, Sorrenti (2009) aponta que, com o surgimento do modernismo na década de 1920, "entram para as antologias para as crianças poetas como Manuel Bandeira e Cassiano Ricardo" (p.25), portanto, esses poemas são aceitos pelo público infantil devido à novidade na escrita. “Dentro dessa perspectiva, a sonoridade torna-se a grande responsável pela iniciação poética e deverá agradar o ouvido da criança" (p.25). Além da sonoridade, a autora atenta para outros elementos que suscitam o interesse pela leitura de poemas considerados para adultos, que é justamente a linguagem inusitada, a adequação temática e a composição.

Em contraposição ao poema Meninos Carvoeiros, o livro B, ao apresentar o poema Se você for inventor invente, explora duas características que interessam às crianças: a ludicidade verbal e a presença dos bichos nos textos:

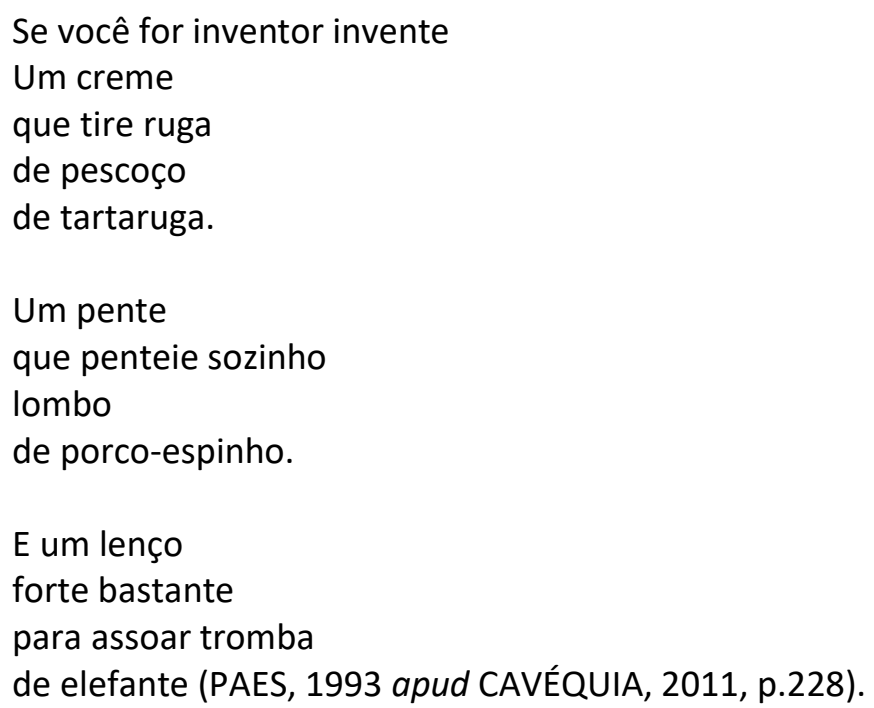

De acordo com Zilberman (2005), os “bichos são apropriados à literatura infantil, porque, a partir de algumas de suas características, possibilitam simbolizar a própria criança" (p.131). 
Além disso, destaca que "os animais correspondem, em primeiro lugar, ao esforço de aproximar leitor e tema do texto. Por isso, predominam bichos domésticos, como cães e gatos (...)” (p.132), conforme se observa no poema de José Paulo Paes. Valendo-se da ludicidade nos versos e acrescentando rimas, o poeta coloca os animais em situações engraçadas e, segundo Zilberman (2005), os textos que colocam os bichos em situações cômicas ou insólitas trazem para o cotidiano das crianças situações que provocam o riso. Nas palavras da autora, o poeta "pode estender ao máximo a criatividade, propondo situações fantásticas ou inverossímeis" (2005, p.140), que, ao encaminhar a fantasia na direção do absurdo, torna o poema surrealista e mágico.

No poema $O$ menino que ganhou um rio, presente no livro $\mathrm{C}$, assim como na poética de Manoel de Barros, os elementos da natureza aparecem com frequência. No entanto, o eu poético, neste texto, traz reminiscências da infância, mais especificamente sobre o presente que ganhara no aniversário. Segue o poema:

Minha mãe me deu um rio.

Era dia de meu aniversário e ela não sabia

o que me presentear.

Fazia tempo que os mascates não passavam

naquele lugar esquecido.

Se o mascate passasse a minha mãe compraria

rapadura

Ou bolachinhas para me dar.

Mas como não passara o mascate, minha mãe me deu um rio.

Era o mesmo rio que passava atrás de casa.

Eu estimei o presente mais do que fosse uma rapadura do mascate.

Meu irmão ficou magoado porque ele gostava do rio igual aos outros.

A mãe prometeu que no aniversário do meu irmão

Ela iria dar uma árvore para ele.

Uma que fosse coberta de pássaros.

Eu bem ouvi a promessa que a mãe fizera ao

meu irmão

E achei legal.

Os pássaros ficavam durante o dia nas margens

do meu rio

E de noite eles iriam dormir na árvore do

meu irmão.

Meu irmão me provocava assim: a minha árvore

Periódico Horizontes - USF - Itatiba, SP - Brasil - e021025 


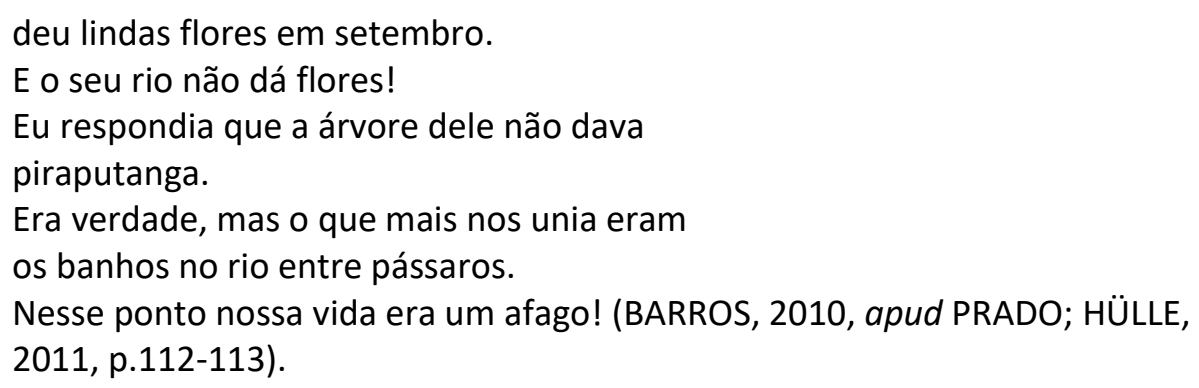

De acordo com Silva (2012), a obra de Manoel de Barros apresenta marcas de um discurso memorialista, como se vê no poema acima, justificando, assim, a escolha por apresentá-lo em uma unidade que trata da aprendizagem e escrita do gênero relato pessoal. Embora o livro não aborde a escrita de poema, fica implícita a ideia de que é possível escrever memórias por meio de outra linguagem que não seja necessariamente a narrativa, assim como fez Manoel de Barros.

O livro Memórias inventadas: as infâncias de Manoel de Barros, que traz esse poema, não foi publicado originalmente para crianças, entretanto, Silva (2012) destaca que esses poemas apresentam um conjunto de "características lúdicas e temáticas facilmente apreciadas por leitores menores" (p.239). Pensar, portanto, na diferenciação de poemas escritos para adultos ou para crianças, torna necessário, de acordo com Bordini (1991), compreender que a produção poética precisa transcender a "tendência à inferiorização de seu destinatário, tratando-o em pé de igualdade e apresentando-Ihe um texto com o mesmo nível artístico que para o adulto" (p.21).

Dessa forma, é possível afirmar que Barros coloca o pequeno leitor em condições de apreciar sua escrita, pois aposta na centralidade da infância. Isso decorre justamente porque "a densidade orgânica dos poemas de Manoel de Barros constrói coerentemente um mundo maravilhoso, particular nas referências a espaços e coisas, mas universal na maneira de observálas" (SILVA, 2012, p.240). No poema em destaque, é possível verificar esse mundo maravilhoso por meio dos elementos da natureza que permearam a infância do eu poético, levando a mãe a presentear os filhos com um rio, com uma árvore coberta de pássaros, e isso fez com que o menino pensasse na vida como um afago.

Por outro lado, como bem destaca Silva (2012), não se trata de um olhar ufanista sobre a natureza, "mas de uma natureza das coisas ínfimas, ao alcance do olhar, das mãos e da imensa curiosidade do menino" (p.242). Por conseguinte, valoriza-se "o modo de ver as coisas e a visão da criança se opõe ao olhar do adulto" (p.242). Além disso, os mais simples objetos, espaços ou 
coisas são, nos textos de Barros, renovados por meio da criação poética. E, ao rememorar os tempos da infância e mostrar outra lógica de relacionamento com os elementos da natureza, dialoga também com o público infantil.

Por fim, no livro D foi selecionado o poema Amor, de Lalau e Laurabeatriz, para pensar as possibilidades poéticas presente no material didático. Conforme já apontado, esse texto é utilizado para a explicitação do conceito de imagens poéticas, todavia, não apresenta possibilidades de aprofundamento na escrita do gênero. Segue o poema:

Amor

É parecido

Com um

Campo florido.

Tem sabor de pudim

De caramelo,

Com casquinha

De açúcar queimado

E cobertura

de marshmallow.

Pode ser também

Quando alguém

Cuida de um neném.

Ou, talvez,

Quando contam

Uma história bonita

Mais de uma vez.

Tem cheiro de sabonete.

Tem gosto de sorvete.

É como um brinquedo.

É como um segredo.

Tem que

Ser grande,

Maior que

O mar.

Tem que

Ser lindo,

De fazer

Chorar (LALAU; LAURABEATRIZ, 2008, apud SANCHEZ, 2011, p.72).

Periódico Horizontes - USF - Itatiba, SP - Brasil - e021025 
Ao longo do poema, é possível perceber que os autores utilizam palavras que criam imagens inusitadas. Isso se dá por meio da comparação que torna a linguagem mais expressiva. Observa-se a associação de ideias para produzir emoção no leitor. O sentimento amor é igualado a alguns elementos que, de certa forma, atraem as crianças, como pudim, caramelo, sorvete, brinquedo. Há também a comparação com alguns elementos da natureza: campo florido e mar, além de compará-lo a algumas ações humanas: cuidar de um neném, contar uma história e chorar.

O poema, ao comparar o amor às diversas sensações, traz os cinco sentidos humanos nas estrofes que o compõe, possibilitando, assim, a percepção de um sentimento abstrato relacionado com elementos do mundo exterior. Com isso, cria imagens que permitem à criança associar o amor com o paladar, por meio da sensação do sabor de pudim, do açúcar queimado e do sorvete. A visão aparece mediante a comparação a um campo florido, o tato fica expresso pela ação de cuidar de um neném, a audição a partir da escuta uma história bonita e, por fim, o olfato leva o pequeno leitor a perceber o amor similar ao cheiro de sabonete.

Desse modo, o poema exemplifica a capacidade que o discurso poético tem de construir imagens visuais, e não apenas sonoras, pois, ao utilizar os sentidos em sua construção, a visão sobressai, já que o leitor é levado a visualizar cada estrofe. Neste sentido, a abordagem das figuras de linguagem é fundamental no trabalho com poemas em sala de aula, pois, como destaca Sorrenti (2009), a linguagem poética possui muitos significados e procura se utilizar de diversos recursos ligados à estilística.

Diante dos apontamentos acima, percebe-se que os livros analisados, em geral, estão preocupados em trazer uma diversidade de poemas, assim como de gêneros textuais. Ao abordarem a ludicidade, a criatividade, a exploração dos jogos sonoros e visuais, até mesmo a abordagem de temas considerados graves, os poemas revelam uma concepção dos autores de livros didáticos sobre a formação de leitor poético. Entretanto, nem sempre as atividades propostas dão conta de explorar a riqueza da materialidade poética, pois são utilizados, frequentemente, como pretexto para trabalhar outros conteúdos, desconsiderando a amplitude da literatura e as vozes das crianças.

Posto isso, percebe-se que os materiais didáticos, bem como certas concepções pedagógicas, estão mais preocupados em formar leitores que respondam a questões e elaborem 
textos considerados úteis, ou seja, tratam os poemas como instrução. Frente a essa situação, é importante destacar que a linguagem literária é carregada de sentidos conotativos, portanto, está longe apenas informar algo, pois, como mostram Wellek e Warren (2003), "a poesia tem muitas funções possíveis. Sua função primordial e principal é a fidelidade à sua própria natureza" (p.35).

Para Wellek e Warren (2003), a linguagem literária "tem seu lado expressivo; ela comunica o tom e a postura do falante ou escritor. E ela não apenas formula e expressa o que diz, mas também quer influenciar a postura do leitor, persuadi-lo e, por fim, modificá-lo" (p.15). O próprio símbolo sonoro da palavra é enfatizado, já que os diversos modelos de "técnicas foram inventados para chamar a atenção para ele, tais como a métrica, a aliteração e padrões sonoros" (p.15). Diante disso, os autores discutem a questão do doce e o útil na literatura e apontam o seguinte:

Quando nos dizem que poesia é 'brincadeira', divertimento espontâneo, sentimos que não se fez justiça nem ao cuidado, à perícia e planejamento do artista nem à seriedade e importância do poema; quando nos dizem, porém, que a poesia é 'trabalho' ou 'ofício', sentimos a violência feita à sua alegria e ao que Kant chamou de 'falta de propósito'. Devemos descrever a função da arte de uma maneira que faça justiça simultaneamente ao dulce e ao utile (Wellek e Warren, 2003, p.24).

Acerca dessa questão, Wellek e Warren (2003) mostram que o útil equivale àquilo "que não é perda de tempo", não a uma forma de "passar o tempo", algo que mereça atenção séria" (p.25). Já o doce representa o "não aborrecimento", "não dever", "sua própria recompensa" (p.25). Neste sentido, é possível afirmar que a dificuldade na formação do leitor poético reside justamente na conciliação entre o doce e o útil e na superação de visões pragmáticas sobre o ensino de língua portuguesa nas escolas, visto que "prazer e utilidade não devem meramente coexistir, mas fundir-se" (p.26).

Corroborando com as proposições dos autores, vale ressaltar que o prazer de ler uma obra literária e, portanto, poemas, pertence a um tipo superior de atividade (doce), já o útil corresponde a uma seriedade que não diz respeito a uma tarefa que deve ser feita, mas uma seriedade estética e de percepção a ser aprendida. Sendo assim, o desafio aos manuais didáticos de língua portuguesa seria a proposição de práticas que visem à formação do leitor poético no 
sentido de conciliar o prazer de uma contemplação que não tem a obrigação de gerar, necessariamente, resultados, mas que trata com importância a criação literária.

\section{Considerações finais}

Este trabalho de análise dos livros didáticos de Língua Portuguesa teve como objetivo central compreender a abordagem conferida aos poemas. Neste sentido, foi possível verificar que os livros trazem diversos poetas que se dedicaram a escrever especificamente para o público infantil, entretanto, apresentam também aqueles que não tinham a infância como destinatária de seus versos, mas que, de certa maneira, são apreciados devido à linguagem, à composição e às temáticas.

Se, de um lado, observou-se em alguns manuais a predominância do ensino de aspectos gramaticais por meio de poemas, como no caso do livro D, por outro lado, em outros casos, foi possível verificar que trazem uma diversidade grande de gêneros textuais e apresentam várias questões que possibilitam diversas discussões. No caso específico dos poemas, percebe-se que conferem um tratamento mais voltado à compreensão dos textos; e a escrita e a oralidade, por vezes, é relegada a um segundo plano.

Diante das análises, cabe questionar se, por meio das propostas examinadas, a criança dos anos iniciais desenvolve habilidades leitoras da linguagem poética e da criação ou se os livros se preocupam apenas em promover a identificação da estrutura do texto e utilizá-los como pretexto para ensinar outros conteúdos. Ao analisar os quatro livros, conforme destacado em outros momentos, foi possível verificar o seguinte: o livro $A$ e o livro C não propõem a produção de poemas, já o livro D sinaliza alguns momentos de escrita, mas não se demora nessa prática, apenas o livro B parece estar mais preocupado com a leitura e a produção.

Diante dessas constatações, percebe-se que o gênero poema não é visto, em geral, como uma potencialidade para a aprendizagem da leitura e da escrita, desconsidera-se a riqueza da linguagem e da expressão que poderiam aparecer nos textos produzidos pelos meninos e meninas dos anos iniciais do ensino fundamental. É evidente que cada livro traz uma concepção de ensino de língua, no entanto, não se pode desconsiderar as potencialidades das crianças ao se colocarem na condição de leitoras e escritoras. 
Considerando que, para explorar as possibilidades da linguagem poética, não podemos ficar encerrados às atividades de análises gramaticais e de estrutura, uma vez que as crianças são sensíveis aos jogos sonoros e verbais, aos ritmos, às rimas e às cadências, é preciso pensar em propostas que não se limitem apenas à utilização do livro didático, pois, enquanto alguns dão conta de explorar as capacidades de leitura e escrita do poema, outros trazem esse gênero somente como subterfúgio para ensinar conteúdos gramaticais que sequer consideram a atração das crianças pela ludicidade verbal.

Frente às análises das propostas de atividades, fica clara a necessidade de superar as concepções de que os poemas devam servir ao ensino de algum conteúdo específico, de que é um gênero menor frente àqueles que circulam na esfera social e que possuem uma utilidade imediata. Além disso, é importante destacar que os livros didáticos, embora tragam propostas que buscam atender as necessidades de leitura e escrita, não podem se constituir em um modelo único a ser utilizado, pois é o (a) professor (a) responsável por avaliar quando esse material contribuirá com sua prática pedagógica na formação de leitores e escritores.

Por fim, torna-se necessário apontar que cabe à escola garantir às crianças o acesso à leitura, análise e escrita dos mais diversos tipos de textos, visto que a formação de leitores e escritores depende da riqueza e variedade de textos apresentados. Mais especificamente no caso dos poemas, faz-se necessário destacar que as crianças são capazes de apreender a linguagem lúdica presente nos versos, portanto, no contexto escolar, o poema não pode se prestar a uma abordagem pragmática e utilitarista.

\section{Referências}

ABRAMOVICH, F. Literatura infantil: gostosuras e bobices. 5. ed. São Paulo: Scipione, 1999.

AGUIAR, V. T.; CECCANTINI, J. L. Uma história a ser contada. In: AGUIAR, V. T.; CECCANTINI, J. L. Poesia infantil e juvenil brasileira. São Paulo: Cultura Acadêmica, 2012, p.11-44.

BORDINI, M.G. Poesia infantil. 2. ed. São Paulo: Ática, 1991.

BRASIL. Parâmetros Curriculares Nacionais (PCNs): Língua Portuguesa - primeiro e segundo ciclos. Brasília: MEC/Secretaria de Educação Fundamental, 1997.

CAVÉQUIA, M. P.Língua portuguesa. 4. ed. São Paulo: Scipione, 2014. 
COELHO, N. C. A poesia destinada às crianças. In: COELHO, N. C. Literatura infantil. São Paulo: Moderna, 2000, p.221-274.

LAJOLO, M.; ZILBERMAN, R. A ruptura com a poética tradicional. In: LAJOLO, M.; ZILBERMAN, R. Literatura infantil brasileira: história e histórias. 6. ed. São Paulo: Ática, 1999, p.145-152.

LÜDKE, M.; ANDRÉ, M. Pesquisa em educação: abordagens qualitativas. São Paulo. EPU, 1986.

MARINHO, A. C.; PINHEIRO, H. O cordel no cotidiano escolar. São Paulo: Cortez, 2012.

MARTHA, A. A. P. Pequena prosa sobre versos. In: AGUIAR, V. T.; CECCANTINI, J. L. (orgs.). Poesia infantil e juvenil brasileira. São Paulo: Cultura Acadêmica, 2012, p.45-71

MEIRELES, C. Ou isto ou aquilo. São Paulo: Giroflé, 1964.

MELLO, A. M. L. O gênero lírico na literatura infantil. In: MELLO, A. M. L; TURCHI, M. Z.; SILVA, V. M. T. (orgs.). Literatura infanto-juvenil: prosa e poesia. Goiânia: Editora da UFG, 1995, p.147-154.

PRADO, A.; HÜLLE, C. Projeto prosa: língua portuguesa. 2. ed. São Paulo: Editora Saraiva, 2011.

SANCHEZ, M. M. Português: projeto buriti. 2. ed. São Paulo: Moderna, 2011.

SILVA, F. C. Manoel de Barros: invenções da infância na escola. In: AGUIAR, V. T.; CECCANTINI, J. L. (orgs.). Poesia infantil e juvenil brasileira. São Paulo: Cultura Acadêmica, 2012, p.237-260.

SORRENTI, N. A poesia vai à escola: reflexões, comentários e dicas de atividades. Belo Horizonte: Autêntica Editora, 2009.

TURCHI, M. Z. Tendências da poesia infanto-juvenil brasileira. In: MELLO, A. M. L; TURCHI, M. Z.; SILVA, V. M. T. (orgs.). Literatura infanto-juvenil: prosa e poesia. Goiânia: Editora da UFG, 1995. p.155-168.

VASCONCELOS, A. Língua portuguesa: aprender juntos. 3. ed. São Paulo: Edições SM, 2011.

VIEIRA, D. O. A abordagem da poesia nos livros didáticos de português. Revista Diálogos Acadêmicos, Fortaleza, v.4, n.1, jan./jun. 2015.

WELLEK, R.; WARREN, A. Teoria da literatura e metodologia dos estudos literários. Trad. Luís Carlos Borges. São Paulo: Martins Fontes, 2003.

ZILBERMAN, R. E para a poesia, não vai nada? In: ZILBERMAN, R. Como e por que ler a literatura infantil brasileira. Rio de Janeiro: Objetiva, 2005, p.127-143.

Recebido em setembro 2019.

Aprovado em fevereiro 2021. 